\title{
Studies on the receptor responsible for vibration induced inhibition of monosynaptic reflexes in man
}

\author{
F. DINDAR AND M. VERRIER \\ From the Neurophysiology Unit, Toronto Western Hospital, Toronto, Canada
}

SYNOPSIS A further attempt has been made to define the receptor responsible for the inhibition of monosynaptic reflexes by vibration in man. Vibration of the tendo Achillis will produce inhibition of the $\mathrm{H}$ reflex even when the muscles of the anterior compartment of the leg are denervated or blocked with local anaesthetic, implying that there are receptors in the posterior compartment capable of producing this effect. However, there is evidence that vibration spreads through the limb. The inhibition is greater when the anterior compartment is innervated indicating that there is a contribution from receptors in this compartment. Stretching the muscles of the posterior compartment alone, or the muscles of the anterior and posterior compartments reciprocally does not influence the inhibition of the monosynaptic reflex by vibration. These observations support the contention that the reduction of the monosynaptic reflex by vibration in man is due to presynaptic inhibition resulting from activation of primary spindle endings.

Vibration of the muscles of a limb in man will produce a powerful inhibition of the monosynaptic reflex (Lance, 1965; De Gail et al., 1966; Hagbarth and Eklund, 1966) but the mechanism of this effect is still unclear.

There is some evidence that the inhibition may be presynaptic. Thus, in animals, the inhibition is accompanied by depolarization of primary afferent nerve fibres, it can be blocked by picrotoxin, and it can occur while the excitability of motoneurones to direct stimulation is unchanged (Gillies et al., 1969; Barnes and Pompeiano, 1970a). In man the evidence is similar but less direct; the inhibition can not be attributed to occlusion in the Ia monosynaptic pathway (Gillies et al., 1970) and, although the monosynaptic reflex is depressed, the excitability of the same motoneurones to other inputs may be unaffected (Delwaide, 1973).

Vibration of a limb could activate muscle receptors and Pacinian corpuscles as well as cutaneous receptors; however Pacinian corpuscles respond optimally to high frequency vibration (Sato, 1961) and inhibition of the monosynaptic reflex can be obtained in a skinned preparation (Gillies et al., 1969), so (Accepted 15 August 1974.) cutaneous receptors are not essential. The responsible receptor therefore probably lies within the muscle. Brown et al. (1967) have demonstrated that, in animals, the primary ending of the muscle spindle is very much more sensitive to vibration than the secondary ending or Golgi tendon organ. The relative sensitivity of the muscle receptors in man has not been established. Direct recording from Ia nerve fibres indicates that primary spindle endings are activated by vibration in man (Hagbarth, 1973) but Eklund (1971) has produced evidence that secondary endings may be activated especially by low frequency vibration applied over the belly of the muscle.

In animals inhibition of the extensor monosynaptic reflex can be produced from a flexor muscle when the vibrator is adjusted to activate only the primary spindle endings (Barnes and Pompeiano, 1970a) but, if a synergist is vibrated, postsynaptic facilitation overwhelms presynaptic inhibition (Barnes and Pompeiano, 1970b). This has led Lance et al. (1973) to postulate that vibration spreads through the limb in man and that the inhibition of the monosynaptic reflex by vibration is 'a complex interaction of group Ia synaptic effects-presynaptic inhibition and 
postsynaptic facilitation from the agonist, and presynaptic inhibition and postsynaptic inhibition from the antagonist'.

Delwaide carried out studies in an attempt to define the receptor responsible for vibration induced inhibition of the monosynaptic reflex in man (Delwaide, 1973). He demonstrated that muscle stretch produced inhibition of the $\mathbf{H}$ reflex that was similar to and occluded that produced by vibration. The inhibition was seen during the dynamic phase of a stretching movement limited to the triceps surae alone, suggesting that it was arising from the primary spindle endings of triceps surae.

In a further attempt to define the receptor responsible for vibration induced inhibition of the monosynaptic reflex we have recorded the degree of inhibition of the $\mathrm{H}$ reflex in normal subjects with the common peroneal nerve blocked with local anaesthetic and in a patient in whom the anterior compartment of the leg was denervated and fibrosed.

\section{METHODS}

The investigation was carried out on 10 normal subjects aged 24 to 42 years (mean 31.4) and one patient with a complete peroneal nerve lesion. This was a 24 year old male who had been involved in a motorcycle accident two years previously. He had sustained a posterior dislocation of the right tibia. At operative reduction, the common peroneal nerve was observed to be bruised and the common peroneal artery disrupted. Three months after the accident there had been no return of dorsiflexion of the toes or ankle. Sensory conduction velocity in the sural nerve was $50 \mathrm{~m} / \mathrm{s}$ but conduction could not be recorded in the peroneal nerve. Needle electrode examination showed no electrical activity of any kind in the anterior compartment of the leg. Some denervation potentials and slight loss of motor units were observed in tibialis posterior and flexor hallucis brevis. At the time of the present investigation the extensor digitorium brevis was wasted and there was wasting of the right anterior compartment which was abnormally firm to touch. The patient was still completely unable to dorsiflex the toes or ankle. There was moderate power in the right gastrocnemius and soleus, although he was unable to hop on this leg. There was sensory impairment in the distribution of the common peroneal nerve. The ankle jerk was within normal limits. On needle electrode examination there was still no insertion activity in the anterior compartment which was considered to be completely fibrosed. There was some reduction of the number of motor units in tibialis posterior and occasional large long duration potentials were observed in this muscle.

Studies were performed with the subject prone and the knee joint in full extension. The leg to be examined was immobilized in a mechanical joint apparatus (Monster et al., 1973) which allowed the ankle to be fixed in any position between $30^{\circ}$ plantarflexion and $15^{\circ}$ dorsiflexion.

Square wave electrical stimuli of $1 \mathrm{~ms}$ duration, generated by a Grass S88 stimulator, were delivered to the popliteal nerve in the popliteal fossa using bipolar surface electrodes positioned to produce a reflex response (H reflex) at the lowest possible threshold and then immobilized with a rubber strap. The stimulator was triggered by a PDP 12 Digital computer programmed to deliver 10 impulses at random intervals of between two and three seconds. The stimulus current was increased in increments until a complete $\mathrm{H}$ reflex recruitment curve had been obtained. Vibration was applied manually to the Achilles tendon with a Wahl Jumbo vibrator (frequency $60 \mathrm{~Hz}$, amplitude $3 \mathrm{~mm}$ undamped). An interval of 90 seconds elapsed between the end of vibration and the subsequent test stimuli to avoid the long lasting effects of vibration (Arcangel et al., $\mathbb{\Phi}$ 工 1971). The compound action potential of the soleus -7 was recorded with surface electrodes, $2 \mathrm{~cm}$ in $\frac{8}{O}$ diameter, the active electrode being placed over the belly of soleus and the reference electrode $8 \mathrm{~cm}$ distally over the tendo Achillis. A $6 \mathrm{~cm}$ square leado plate placed over the upper gastrocnemius acted as an earth (ground) electrode.

Action potentials were amplified by a Tektronix type RN 564 amplifier (filter setting $0.1 \mathrm{~Hz}$ and 0.1 $\mathrm{mHz}$ ) and displayed on a Tektronix type 2A 60 storage oscilloscope. This signal was digitalized $(1000 / \mathrm{s})$ by a computer (PDP 12). Ten responses were averaged and plotted with an incremental plotter (Complot DP1-1). Peak to peak amplitudes of the compound action potentials were measured from the plotting paper.

When the subject appeared settled, a control $\mathbf{H}$ reflex recruitment curve was obtained with the ankle in $30^{\circ}$ plantarflexion. By applying vibration at each stimulus level, the $\mathbf{H}$ reflex recruitment curve during vibration could be obtained simultaneously. In eight normal subjects the recruitment curve was then repeated with the ankle in $15^{\circ}$ dorsiflexion.

In five normal subjects complete block of the peroneal nerve was produced by local injection of $10 \mathrm{ml} 1 \%$ xylocaine. The completeness of the block was verified by needle electrode examination of the anterior tibial muscle. The $\mathrm{H}$ reflex recruitment curve with and without vibration was obtained in $30^{\circ}$ 

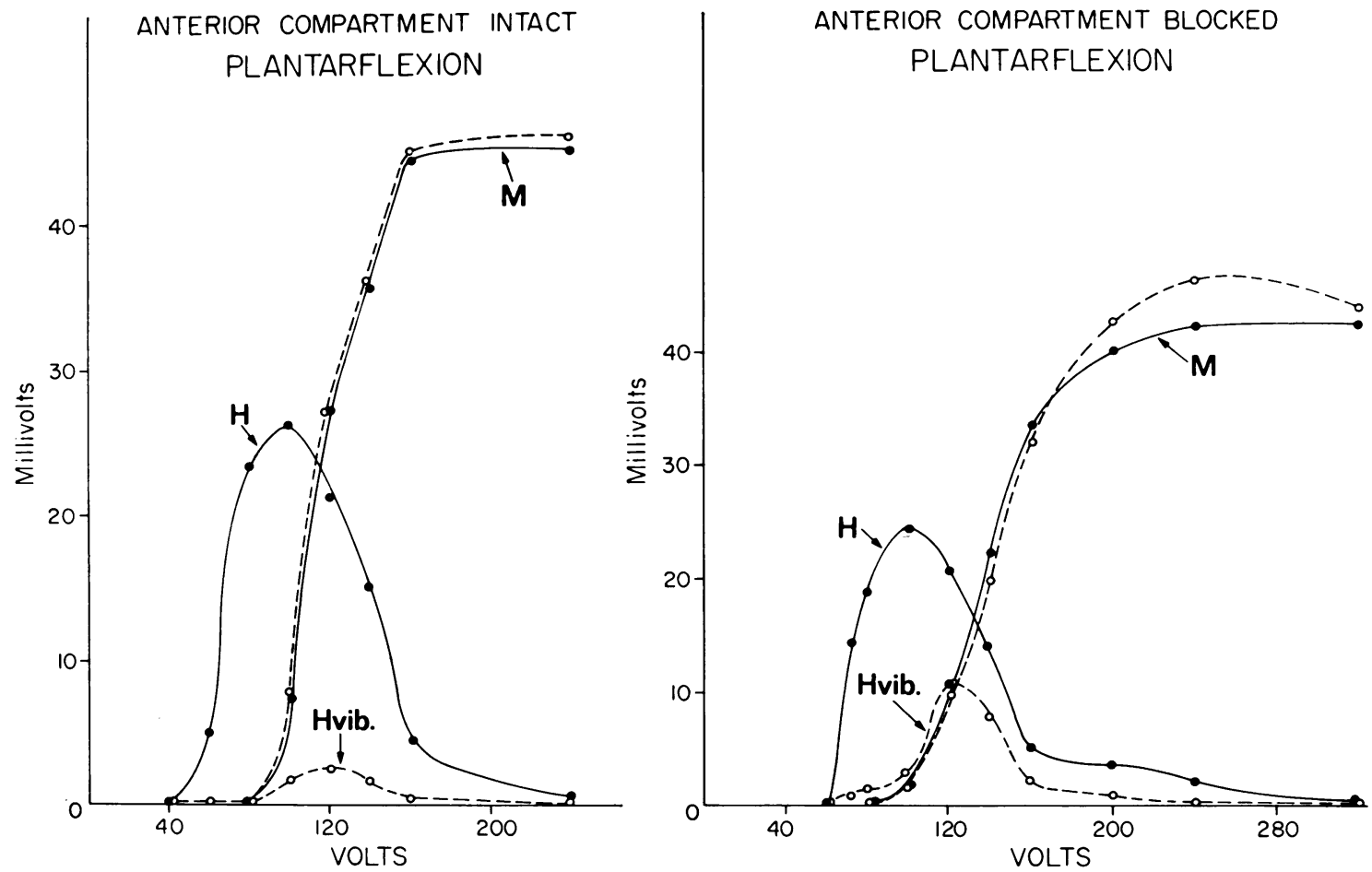

FIG. $1 A$ comparison of the inhibition of the $H$ reflex produced by vibration in one subject $(P . A$.$) before and$ after peroneal nerve block. Inhibition of the $H$ reflex by vibration can still be obtained with the common peroneal nerve blocked but the inhibition is greater when the anterior compartment is innervated.

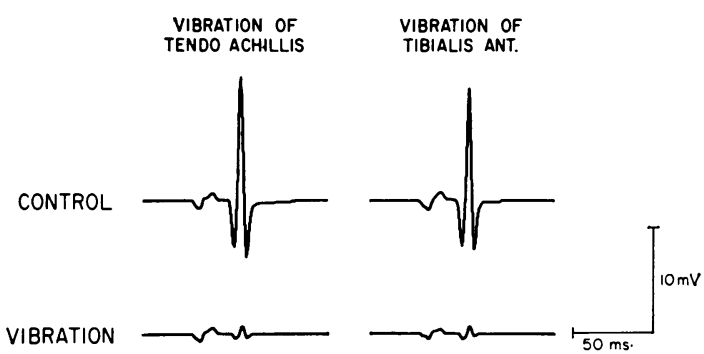

FIG. 2 A comparison of the inhibition of the $H$ reflex produced by vibration applied to the tendo Achillis and by vibration applied over the belly of tibialis anterior in a subject with the common peroneal nerve blocked. The foot is in $30^{\circ}$ plantarflexion. The degree of inhibition is similar in both instances suggesting that vibration spreads across the leg.

plantarflexion. In three of these subjects the recruitment curve was repeated with the ankle in $15^{\circ}$ dorsiflexion.

\section{RESULTS}

EFFECT OF COMMON PERONEAL NERVE BLOCK In five subjects the common peroneal nerve was blocked by local injection of $1 \%$ xylocaine. A complete block was obtained in all subjects. This was substantiated by a total inability to dorsiflex the ankle or toes or evert the foot, sensory loss in the distribution of the peroneal nerve, and absence of any motor unit activity on needle electrode examination of the anterior compartment. Only the peroneal nerve was blocked and there was no weakness of any other muscle group. The block lasted $2 \frac{1}{2}$ to five hours (mean 4.0 hours). During the block the $\mathrm{H}$ reflex was suppressed by vibration (Fig. 1, Table 1) implying that the afferent nerves from the anterior compartment are not essential for this effect. The inhibition of the $\mathrm{H}$ reflex by vibration, however, was greater when the anterior compartment was innervated (Fig. 1, Table 1).

EFFECT OF VIBRATION UPON THE H REFLEX IN A PATIENT WITH COMPLETE PERONEAL NERVE PALSY AND FIBROSIS OF THE ANTERIOR COMPARTMENT In 

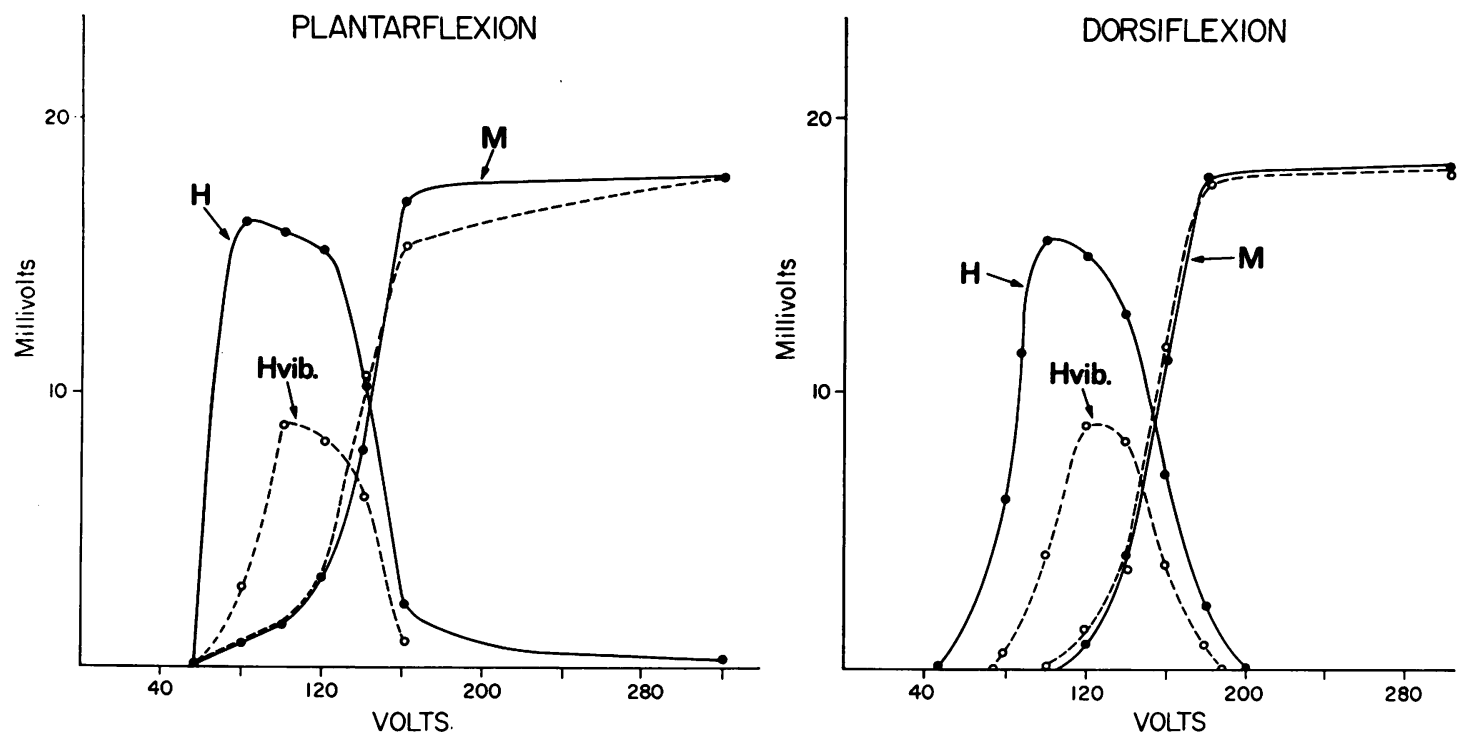

FIG. 3 H-reflex recruitment curves in a normal subject (B.R.). Even though the ankle has moved from $30^{\circ}$ plantarflexion to $15^{\circ}$ dorsiflexion there is no alteration in the $\mathrm{H}$ vibration/H control ratio.

TABLE 1

DEGREE OF H REFLEX SUPPRESSION BY VIBRATION IN FIVE NORMAL SUBJECTS WITH AND WITHOUT COMMON PERONEAL NERVE BLOCK*

\begin{tabular}{llcccc}
\hline Subject & Sex & $\begin{array}{c}\text { Age } \\
(\text { a) }\end{array}$ & \multicolumn{3}{c}{ H vibration/H control } \\
\cline { 4 - 6 } & & & $\begin{array}{c}\text { Control } \\
(\%)\end{array}$ & $\begin{array}{c}\text { Peroneal } \\
\text { nerve block } \\
(\%)\end{array}$ & $\begin{array}{c}\text { Difference } \\
(\%)\end{array}$ \\
\hline M.V. & F & 25 & 2.9 & 32.9 & 30.0 \\
F.D. & M & 31 & 29.5 & 42.9 & 13.4 \\
P.A. & M & 37 & 9.6 & 44.1 & 34.5 \\
B.G. & M & 39 & 30.6 & 55.8 & 25.2 \\
L.L. & F & 27 & 20.4 & 34.5 & 14.1 \\
\hline & & & & Mean & 23.4 \\
& & & & $t$ & 5.5 \\
& & & & P & $>0.01$ \\
\end{tabular}

* The inhibition can still be obtained after the nerve block but is less than when the anterior compartment is innervated.

this patient, in whom the dorsiflexors of the ankle were denervated and fibrosed, vibration of the tendo Achillis produced inhibition of the $\mathrm{H}$ reflex. The $\mathrm{H}$ vibration/ $\mathrm{H}$ control ratio was $43.5 \%$.

EFFECT OF VIBRATION OF THE ANTERIOR COMPARTMENT DURING COMPLETE BLOCK OF THE PERONEAL
TABLE 2

DEGREE OF H-REFLEX SUPPRESSION IN EIGHT NORMAL $\bar{\sigma}$ SUBJECTS WITH ANKLE IN $30^{\circ}$ PLANTARFLEXION AND IN $15^{\circ}$ DORSIFLEXION*

\begin{tabular}{llcrcc} 
Subject & Sex & $\begin{array}{c}\text { Age } \\
(a)\end{array}$ & & \multicolumn{3}{c}{ H vibration/H control } \\
\cline { 3 - 6 } & & & $\begin{array}{c}30^{\circ} \\
\text { Plantarflexion } \\
(\%)\end{array}$ & $\begin{array}{c}15^{\circ} \\
\text { Dorsiflexion } \\
(\%)\end{array}$ & $\begin{array}{c}\text { Difference } \\
(\%)\end{array}$ \\
\hline 1. J.D. & M & 42 & 64.7 & 24.0 & -40.7 \\
2. G.T. & M & 36 & 23.6 & 25.5 & +1.9 \\
3. F.D. & M & 31 & 29.5 & 25.0 & -4.5 \\
4. M.V. & F & 25 & 2.9 & 3.0 & +0.1 \\
5. M.B. & M & 27 & 7.1 & 10.0 & +2.9 \\
6. L.L. & F & 27 & 20.4 & 56.9 & +36.5 \\
7. P.B. & F & 26 & 3.2 & 12.5 & +9.3 \\
8. B.R. & F & 24 & 54.5 & 56.6 & +2.1 \\
\hline Mean & & 29.8 & 25.7 & 26.6 & +0.9
\end{tabular}

* There is no significant difference in the degree of suppression when the flexor or extensor muscles are stretched.

NERVE In five subjects the vibration was applied to the tibialis anterior during complete block of the common peroneal nerve. The $\mathrm{H}$ reflex was suppressed virtually to the same extent as when the vibration was applied to the tendo Achillis (Fig. 2) suggesting that there is significant spread of the vibratory stimulus through the leg. 
TABLE 3

EFFECT OF ANKLE POSITION ON INHIBITION OF H REFLEX BY VIBRATION IN THREE NORMAL SUBJECTS WITH COMMON PERONEAL NERVE BLOCK*

\begin{tabular}{lccccc}
\hline Subject & Sex & $\begin{array}{c}\text { Age } \\
\text { (a) }\end{array}$ & & \multicolumn{3}{c}{ H vibration/H control } \\
\cline { 3 - 6 } & & & $\begin{array}{c}30^{\circ} \\
\text { Plantarflexion } \\
(\%)\end{array}$ & $\begin{array}{c}15^{\circ} \\
\text { Dorsiflexion } \\
(\%)\end{array}$ & $\begin{array}{c}\text { Difference } \\
(\%)\end{array}$ \\
\hline 1. M.V. & F & 25 & 32.9 & 5.4 & +26.5 \\
2. F.D. & M & 31 & 42.9 & 13.6 & +29.3 \\
3. L.L. & F & 27 & 34.5 & 66.7 & -32.2 \\
\hline
\end{tabular}

* Stretching the muscles of the posterior compartment has no consistent effect upon the degree of inhibition.

EFFECT OF ANKLE POSITION ON THE H VIBRATION/H CONTROL RATIO In eight normal subjects the maximum $\mathrm{H}$ vibration/ $\mathrm{H}$ control ratio was measured with the ankle in $30^{\circ}$ plantarflexion and in $15^{\circ}$ dorsiflexion. The mean $\mathrm{H}$ vibration/ $\mathrm{H}$ control ratio in plantarflexion was $25.8 \%$ and in dorsiflexion $26.7 \%$. The mean difference of $0.9 \%$ is not significant (Fig. 3, Table 2). Thus stretching the anterior and posterior compartments reciprocally has no significant effect on the degree of suppression of the $\mathrm{H}$ reflex.

EFFECT OF ANKLE POSITION ON THE H VIBRATION/ H CONTROL RATIO IN SUBJECTS WITH COMMON PERONEAL NERVE BLOCK In three subjects with complete block of the common peroneal nerve the inhibition of the $\mathrm{H}$ reflex by vibration was measured with the ankle in $30^{\circ}$ plantarflexion and in $15^{\circ}$ dorsiflexion. Again there was no consistent change (Table 3 ).

\section{DISCUSSION}

Vibration of the tendo Achillis can result in inhibition of the $\mathrm{H}$ reflex even when the common peroneal nerve has been blocked with local anaesthetic or when there has been complete denervation and fibrosis of the muscles of the anterior compartment of the leg. Evidently, in man, activation of receptors of the antagonistic muscles in the anterior compartment is not essential for this effect and such profound inhibition from spread of vibration to thigh muscles seems unlikely.

This finding substantiates the observations of Delwaide (1973) that stretching of the muscles of
TABLE 4

KNOWN SEGMENTAL EFFECTS ON EXCITABILITY OF EXTENSOR Ia MONOSYNAPTIC ARC OF ACTIVITY IN VARIOUS MUSCLE RECEPTORS THAT COULD BE ACTIVATED BY VIBRATION

\begin{tabular}{lccccc}
\hline & \multicolumn{2}{c}{ From extensor } & & \multicolumn{2}{c}{ From flexor } \\
\cline { 2 - 3 } \cline { 5 - 6 } & $\begin{array}{c}\text { Pre- } \\
\text { synaptic }\end{array}$ & $\begin{array}{c}\text { Post- } \\
\text { synaptic }\end{array}$ & & $\begin{array}{c}\text { Pre- } \\
\text { synaptic }\end{array}$ & $\begin{array}{c}\text { Post- } \\
\text { synaptic }\end{array}$ \\
\hline $\begin{array}{c}\text { Primary } \\
\text { ending }\end{array}$ & - & + & & - & - \\
$\begin{array}{c}\text { Secondary } \\
\text { ending } \\
\text { Golgi tendon } \\
\text { organ }\end{array}$ & - & - & & & - \\
\hline
\end{tabular}

the posterior compartment alone can produce inhibition of the $\mathrm{H}$ reflex suggesting that the responsible receptor lies in the posterior compartment.

The main oligosynaptic reflex effects of muscle receptors upon the extensor motoneurone pool are summarized in Table 4 . Since the monosynaptic reflex can still be inhibited by vibration after spinal cord transection, any polysynaptic reflex effects of these receptors involving supraspinal centres can probably be ignored. Receptors in the posterior compartment (left side of Table 4) that might result in inhibition of the monosynaptic reflex include the primary spindle ending (if presynaptic inhibition exceeds postsynaptic facilitation) the secondary ending, and the Golgi tendon organ.

Stretching of the posterior compartment when the anterior compartment was blocked produced no consistent change in the degree of inhibition. This state of affairs could occur if the inhibition arose from the primary spindle ending (although the sensitivity of the primary ending to vibration is increased by stretch (Matthews, 1972) the central effects would cancel), or the Golgi tendon organ whose sensitivity to vibration is probably unaltered by passive stretch; but this observation would not be expected if the inhibition arose exclusively from the secondary ending.

With the common peroneal nerve blocked, vibration of the anterior compartment produced substantial inhibition of the $\mathrm{H}$ reflex suggesting that vibration, of the type used in this study, does spread through the leg and activate receptors in other muscles. It is likely that vibration 
applied to the tendo Achillis spreads in the reverse direction. In support of this the inhibition produced by vibration of the tendo Achillis is greater when the anterior compartment is innervated, implying that there is activation of receptors in the anterior compartment that have inhibitory effects on the extensor motoneurone pool (Table 4). It is reasonable to assume that it is the same class of receptor that is activated in both instances. If the secondary endings are excluded as argued above, a predominance of presynaptic inhibitory effects could best account for this observation and the failure of reciprocal stretching of the anterior and posterior compartments to influence the degree of vibration induced inhibition. From the known differential sensitivities of muscle receptors presynaptic inhibition from the primary spindle ending rather than the Golgi tendon organ would be the most likely. These observations, therefore, offer some support for the contention that the reduction of the monosynaptic reflex by vibration in man is due to presynaptic inhibition resulting from activation of the primary spindle endings.

The authors are grateful to Norwich Pharmaceutical Products Limited for the use of the rotational joint apparatus.

\section{REFERENCES}

Arcangel, C. S., Johnston, R., and Bishop, B. (1971). The achilles tendon refiex and the H-response during and after tendon vibration. Physical Therapy, 51, 889-902.

Barnes, C. D., and Pompeiano, O. (1970a). Inhibition of monosynaptic extensor reflex attributable to presynaptic depolarization of the group Ia afferent fibers produced by vibration of flexor muscle. Archives Italiennes de Biologie, 108, 233-258.

Barnes, C. D., and Pompeiano, O. (1970b). Presynaptic and postsynaptic effects in the monosynaptic reflex pathway to extensor motoneurons following vibration of synergic muscles. Archives Italiennes de Biologie, 108, 259-294.

Brown, M. C., Engberg, I., and Matthews, P. B. C. (1967). The relative sensitivity to vibration of muscle receptors of the cat. Journal of Physiology, 192, 773-800.

De Gail, P., Lance, J. W., and Neilson, P. D. (1966). Differential effects on tonic and phasic reflex mechanisms produced by vibration of muscles in man. Journal of Neurology, Neurosurgery, and Psychiatry, 29, 1-11.

Delwaide, P. J. (1973). Human monosynaptic reflexes and presynaptic inhibition. An interpretation of spastic hyperreflexia. In New Developments in Electromyography and Clinical Neurophysiology, vol. 3, pp. 508-522. Edited by J. E. Desmedt. Karger: Basel.

Eklund, G. (1971). On muscle vibration in man; an amplitude-dependent inhibition, inversely related to muscle length. Acta Physiologica Scandinavica, 83, 425-426.

Gillies, J. D., Lance, J. W., Neilson, P. D., and Tassinari, C. A. (1969). Presynaptic inhibition of the monosynaptic reflex by vibration. Journal of Physiology, 205, 329-339.

Gillies, J. D., Lance, J. W., and Tassinari, C. A. (1970). The mechanism of the suppression of the monosynaptic reflex by vibration. Proceedings of the Australian Association of Neurologists, 7, 97-102.

Hagbarth, K. E. (1973). The effect of muscle vibration in normal man and in patients with motor disorders. In New Developments in Electromyography and Clinical Neuro. physiology, vol. 3, pp. 428-443. Edited by J. E. Desmedt. Karger: Basel.

Hagbarth, K.-E., and Eklund, G. (1966). Motor effects of $\frac{\vec{\sigma}}{\mathcal{G}}$ vibratory muscle stimuli in man. In Muscle Afferents and $\mathbb{\mathbb { D }}$ Motor Control, pp. 177-186. Edited by R. Granit. $\frac{(\mathbb{D}}{}$ Almqvist and Wiksell: Stockholm.

Lance, J. W. (1965). The mechanism of reflex irradiation $\bar{D} T$ Proceedings of the Australian Association of Neurologists, $3, \mathrm{C}$ 77-81.

Lance, J. W., Burke, D., and Andrews, C. J. (1973). The reflex effects of muscle vibration. Studies of tendon jerkec irradiation, phasic reflex inhibition and the tonic vibration reflex. In New Developments in Electromyography and Clinical Neurophysiology, vol. 3, pp. 444-462. Edited by J. E. Desmedt. Karger: Basel.

Matthews, P. B. C. (1972). Mammalian Muscle Receptors and their Central Actions, p. 172. Monographs of the Physiological Society No. 23. Arnold: London.

Monster, A. W., Herman, R., Meeks, S., and McHenry, J. (1973). Cooperative study for assessing the effects of a pharmacological agent on spasticity. American Journal of Physical Medicine, 52, 163-188.

Sato, M. (1961). Response of Pacinian corpuscles to sinusoidal vibration. Journal of Physiology, 159, 391-409. 